\title{
La Decadencia del Cuento en el Perú.
}

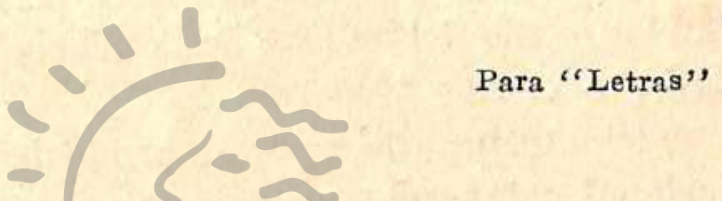

En la Historia Literaria del Perú se nota una marcada prosperidad en el género poético. La poesía encuentra su ambiente y el camino franco, desde el cantar popular hasta la máxima expresión de nuestros grandes poetas. Los demás géneros literarios no gozan de igual fortuna. ¡No hablemos de la novelar, género masculino y viril del que tenemos tan raros representativos. Pero respecto al cuento, síntesis del buen decir, de la imaginación, de la comedia y del drama, es donde se observa animadversión.

Es así como en el Perú existen mas de cien poetas, según estadística literaria de Emilio Champion, pero no se admite mas de un "conteur", para no usar la palabra "cuentista" que tiene en Lima significado mendaz. Tenemos un cuentista para el exterior. Ventura García Calderón; y un gran cuentista nacional Enrique López Albújar. Cuando aparecen nuevas firmas los críticos dicep cómodamente: No está mal, pero no hay como el otro...

Sin embargo, la realidad viviente es distinta. El público, el gran público, busca ávidamente el cuento. El público 


\section{$-366-$}

formado por centenares de gente que salen de los rascacielos corriendo en pos del omnibus o del tranvía, para ir a su casa; ese público de trabajadores del pensamiento y del músculo, se detiene una vez cada semana en un puesto de revistas y compra Leoplán, El Suplemento, Para Ti, los suplementos de La Nación y la Prensa de Buenos Aires; compra Ecran y Zig Zag de Chile; Carteles de la Habana; compra todo de todas partes para leer unos cuantos cuentos en el tranvía o en la paz del hogar. Cuentos de amor, de humorismo, de acción y de odio, cuentos campesinos y sicológicos. Y sobre todo cuentos policiales.

El cinema y el cuento llenan de fantasías nuestra soledad en medio del bullicio de la urbe y realizan un rol importante en la vida moderna.

El escritor de cuentos produciendo para el magazine nacional representa un valioso servicio social ayudando a descansar amablemente un cuarto de hora.

¿Qué dicen los críticos de esto? Dejemos el arte por el arte, el arte "inconsutil" o "alquitarado" y no se cuantas cosas mas. Pero hoy dia, después del tráfago de los jirones repletos de tráfico,r de la asifixila delascensor o del ruido del subterráneo, la multitud lee cuentos. En las cubiertas de los transatlánticos o en los asientos de los aviones, las revistas ofrecen cuentos con preciosas ilustraciones para olvidar por unos momentos la prosa del vivir. Y el cuento dá vida a Revistas, editores, escritores, dibujantes, vendedores, etc., etc.

En Argentina surge ya una pléyade de "conteurs" magníficos. Ya pasó la etapa de copiar cuentos del "THE SATURDAY EVENING POST". Ahora surgen inclusos cuentistas policiales con éxito evidente como Yamandú Rodríguez que firma John Moreyra cuando ensaya el género.

En Ecuador suige otro grupo brillante de conteurs como de la Cuadra, Gallegos Lara y otros. En Chile, después 
de Mariano Latorre, nuevos cuentistas encuentran acogida y ambiente, alentados por el público sin preocuparse de los críticos.

¿Y en el Perú? No puede decirse que no tenemos "conteurs". Después de los grandes cuentistas García Calderón, López Albújar y Clemente Palma, surgen Diez Canseco, Arguedas, Alegre, Huidobro, Ríos Pagaza y muchos mas, sin contar con otros de ayer que son hoy "los hombres olvidados" como escritores de cuentos. Algunos dejaron de escribirlos por falta de publicidad. Sin revistas y sin diarios que acojan el cuento y sin estímulo económico a los autores, nuestros cuentistas olvidan el género. Solo de vez en vez aparece esporádicamente y como "colaboración" algún cuento. Mientras las publicaciones periódicas o diarias, copian cuentos de Federico Boutet, Andrés Birabeau, Arkadio Averchenko y todavía de Mark Twain. Es una de las secciones mas lé́das del diario o magazine.

El único "conteur" peruano que cobra hoy honorarios, es Carlos Parra del Riego, cuyos últimos cuentos en "LEOPLAN" son admirables Pero Parra del Riego escribe gracias a la Argentina. En el Perú escribiría informes oficiales o municipales.'

¿Por qué este desdén por el cuento en el Perú? El problema es digno de estudiarlo por su trascendencia social y
económica. Social, por que matamos a nuestros escritores para copiar a los extranjeros. Y económica, por que se descapitaliza un material que en cualquier país es bien pagado y aumenta el interés de las publicaciones.

Para descubrir las mas importantes razones, cabría examinar si nuestros cuentistas se han esforzado por la forma, han pulido la estructura del cuento y lo han puesto lejos del alcance popular. O to han hecho excesivamente de tierra adentro por el abuso de nombres indígenas, haciéndolo incomprensible al gran público. O no han tocado problemas ac- 
tuales, sea en el amor, en la lucha por la existencia y además no han coincidido con el modo de sentir y pensar de las multitudes en el momento actual.

Otra razón interesante puede ser la intromisión de la política en el gremio y en el género. Los críticos y los escritores se dejan llevar de la moda política imperante y tratan de buscar la emoción política, llamada "emoción social", orientando el cuento según las tendencias políticas imperantes. Pero olvidan que mientras buscan esa orientación o dan con el clavo en la interpretación del "alma de la raza", o en la crítica al orden reinante, el público lee ávido a Pitigrilli, Wallace, Openheim y otros. Y cuánto crítico que hace gestos desdeñosos a la producción nacional, tiene tal vez en su mesa de noche una novela policial de la serie de Sexton Blake....

Esta razón es quizá la mas valedera. En el Perú se cultivó el cuento con éxito en el siglo pasado, según puede verse en nuestra historia literaria, pero el cuento acabó con la muerte de "Variedades", como expresión constante del género. Los últimos diez años han sido políticamente fatales para el cuento. ¿Pero qué importa eso? se dirá por ahí con una sonrisa. Importa, pues cada semana salen del Perú centenares de soles por leer cuentos en TIPERARY, AVENTURA y otras revistas de igual estofa.

$\mathrm{Y}$ así llegamos a lo último del género, el policiaco. E1 cuento policial fué visto con desdén,..como las novelas folletinescas de Perez Escrich o de Carlota Bramé, que en paz descansen. Las novelas de Conan Doyle, ingenuas y pesadas hoy día, fueron superadas por Edgard Wallace. Aunque las desdeñe Gabriel D'Anunzio, es aplastante confesar que aquellas han alcanzado millonadas de ediciones en todos los idiomas. Ultimamente Georges Simenon ha elevado a categoría de arte la novela policial; a un arte sutil y encantador. 
La investigación policial novelada en un marco brumoso de melancolía suave, con la honda poesía trágica que surge del ambiente cosmopolita y nervioso de la sociedad urbana actual.

En la actualidad el cuento policial no puede faltar en los grandes diarios o magazines. Discútase cuanto se quiera su categoría artística, pero es una realidad social viviente. Los nombres de Openheim, Agatha Cristhi y otros son bien cotizados en este género. Son como los crucigramas, útiles como higiene mental. Nadie los desdeña y quien lo hace no es sincero.

En el Perú todavía no ha surgido el cuento policial. El cuento penal de López Albújar, iniciando la presentación de casos jurídicos, será seguido poy el cuento procesal, o sea de investigación. El género es difícil, exige positivo talento, imaginación y aptitud dramática, además de disposición de "conteur".

Género tenido a menos en el Perú y desdeñado por el arte puro, cobrarảalilguna vez categoríacsuperior. Por lo menos con mas derechogy autoridad morabque la exaltación del crimen a categoría artística con Tomás de Quincey y del vicio con Poe o Wilde. Y sin embargo Gastón Leroux, el famoso novelista policial francés, nos enseña un derrotero de la que puede hacerse en nuestro país, cuando escribe su popularísima novela "LA ESPOSA DÊL SOL", novela curiosa, anacrónica, pero interesante sin ninguna duda. Llena de persecusiones pintorescas desde Lima a Cajamarca y de Cuzco a las Islas del Titicaca, tras las momias sagradas de los Incas y por el amor de una virgen del Sol.

El cuento tiene hoy no solo trascendencia literaria, sino social. Si en el Perú no está al servicio de las multitudes, es por que ni diarios ni revistas ni editoriales estimulan su producción. A1 hablar de la decadencia del cuento, no pre- 
tendemos significar que su calidad literaria ha disminuido, sino que por las causas anotadas, la producción no sigue la exitosa línea que en otros países.

Lima, octubre de 1937.

Emilio Romero.

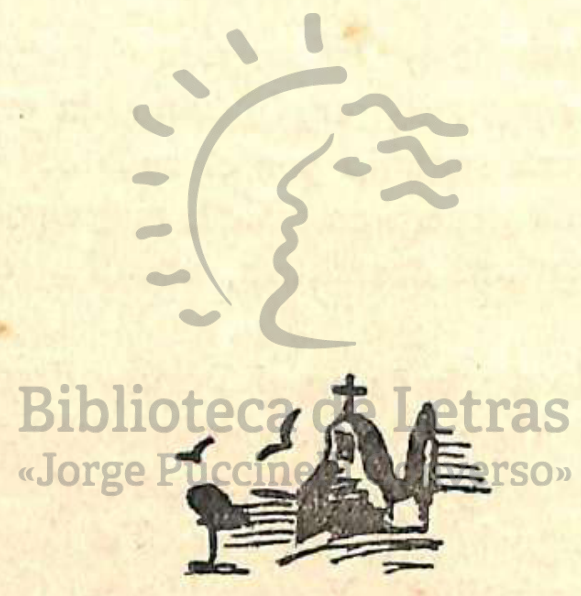

